complications. Under the first named he deals with new methods of miotic treatment. Under trachoma he discusses the rôle of sulphanilamide in the treatment and helps to correct extravagant ideas. The question of iontophoresis with a 1-200 to $1-100$ solution of quinine bisulphate in the treatment of trachoma is also discussed. IV. L. Cooper, in the Arch. of Ophthal. (1940) has claimed good results from this treatment, especially when the cornea is involved, and has found it particularly useful in such cases as relapse after sulphanilamide treatment.

The plates, 39 in number and some of them in colour, have been well chosen and admirably reproduced; and the whole volume is a very good 23 shillings' worth.

Ophthalmic Nursing. By Maurice H. Whiting, O.B.E., Pp. 1.57, Figs. 54. J. and A. Churchill, Limited. 1941.

That this book is now in its third edition is a tribute to its suitability for the purpose for which it was written. Although the author states in his preface that only a small space has been devoted to anatomy, he manages by a strict economy of words to convey as much useful information as many others do in far more pages. The same is true of the sections dealing with diseases and injuries of the eye.

The remainder of the book is concerned with problems bearing more immediately on nursing and there are chapters dealing with therapeutics, methods of treatment, operations, and nursing of surgical and non-surgical cases. These embody the practices adopted at Moorfields, and as these are the result of more than a century of experience, their value needs no emphasis.

The principal changes in the new edition as compared with the old are that it includes references to the use of sulphanamide, and contains a short section on the treatment of gas burns of the eye.

\title{
CORRESPONDENCE
}

\section{HYPEREMESIS GRAVIDARUM}

To the Editors of THE BRITISH JUURNAL OF OPHTHALMOLOGY.

DEAR SIRS-Following the annotation in the September number of the Journal, I read with exceptional interest Professor Ballantyne's article in the Journal of Obstetrics and Gynaecology of the British Empire on the ocular complications in hyperemesis gravidarum. In the annotation you suggest that it would be of interest to obtain 
information as to the occurrence of ocular complications in hyperemesis gravidarum from other obstetrical institutions.

The Rotunda Hospital has during the last six years been responsible for 28,830 deliveries but I have not been called upon to investigate a single case of hyperemesis gravidarum. It is very probable that as Professor Ballantyne suggests, a slight loss of vision passes unnoticed in the presence of severe vomiting, but as it has been my routine to carry out an ophthalmoscopic examination on every patient complaining of loss of vision, I think the condition must be rare. As further evidence of the rarity of the condition, the present Master of the Rotunda Hospital-Dr. Ninian Falkiner -tells me that in 15 years obstetrical practice he has never encountered a loss of vision in association with this condition.

\section{Yours faithfully,}

L. B. SOMERVILLE-LARGE.

17, Fitzwilliam Place, DUBLIN

October, 22, 1941.

\section{CACOETHES SCRIBENDI}

\section{To the Editors of THE BRITISH JOURNAL OF OPHTHALMOLOGy.}

DEAR SIRS,-Sir Stewart Duke-Elder has crushed your annotation which appeared on pages 496 and 497. This is a pity, for the article was evidently written in lighter vein than most of your contributions. Through its very severity the letter from Sir Stewart may in some produce a smile, and indeed the subject recalls certain articles which have appeared recently in your contemporary "Punch" over the initials " A.P.H."

One is glad to hear, however, that the Army has gone one better than Moorfields and that the soldier now departs after his examination wearing his new spectacles.

Whilst the medical department of the War Office is to be congratulated on this change, it is not a change de novo, for a similar arrangement was in force in France in 1916 to 1918 with the B.E.F. and due credit should be allowed to Sir William Lister and those in authority over the ophthalmic services of the Army at that period.

$$
\begin{aligned}
& \text { I am, etc., } \\
& \text { FRANK JULER, } \\
& \text { Colonel L/R.A.M.C. }
\end{aligned}
$$

96, HaRLEy STREET, W.1

November 10, 1941. 